\title{
Dental Fear under Rated Yet Significant
}

\author{
S. Lakshmi Priya, Joyson Moses, BN. Rangeeth, S. Sivakumar
}

Department of Pedodontics, Thai Moogambikai Dental college and hospital, Chennai

\begin{abstract}
Background: Extreme dental fear is a universal problem among children. The dental condition of patients with dental fear is generally worse than the condition of those without dental fear. The aim of the study was to assess the intensity of dental fear in children using Wong-Baker faces pain scale. Materials and Methods: A total of 110 patients in the age range of 8-11 years were recruited for the study. Dental fear was assessed using a structured questionnaire. Data was gathered, computed and statistically analysed to determine the most and the least fearful dental situation for children. Results: Younger children expressed more fear than older children. Fear of injections and sound of drill was most common among children of all the age groups. Conclusion: Dental fear leads to avoidance of dental treatment. The child should be taught that the dental office is not a place to fear and dentistry should never be employed by the parents as a threat or punishment.
\end{abstract}

Keywords: dental fear, children, fear rating scale

Cite This Article: S. Lakshmi Priya, Joyson Moses, BN. Rangeeth, and S. Sivakumar, "Dental Fear under Rated Yet Significant.” International Journal of Dental Sciences and Research, vol. 2, no. 4A (2014): 12-14. doi: 10.12691/ijdsr-2-4A-4.

\section{Introduction}

Fear is a primal emotion and is of great value when given proper direction and control. Since fear producing stimuli can cause actual harm to the child, fear is a protective mechanism for self preservation. Extreme dental fear is a universal problem among children [1]. Most commonly children exhibit fear of unknown which leads to avoidance of treatment. Fear in dentistry could be attributed to many factors such as child's age, level of physical and mental maturity; parent's attitude towards dental treatment [2]. The intensity of dental fear varies among children and cannot be generalized. It is reported that $5 \%$ to $52 \%$ of the children experience such degrees of

dental fear/anxiety that makes providing treatment difficult $[3,4]$. It is believed that the exogenous type of fear relates to a direct or indirect traumatic experience ${ }^{5,6}$. Measurement of dental fear among children has been done by various methods like Psychometric scales, Physiological scales and Projective techniques. Many of these scales used numbering, ranking or color coding to assess dental fear. In the early 80s, Wong-Baker Pain Rating Scale which was introduced by Dr Donna Wong and Cooney Baker utilized a series of facial expressions, with numbers assigned to each face to quantify pain. The aim of the present study was to assess the intensity of dental fear among 8-11 year old children using WongBaker rating scale (Figure 1).
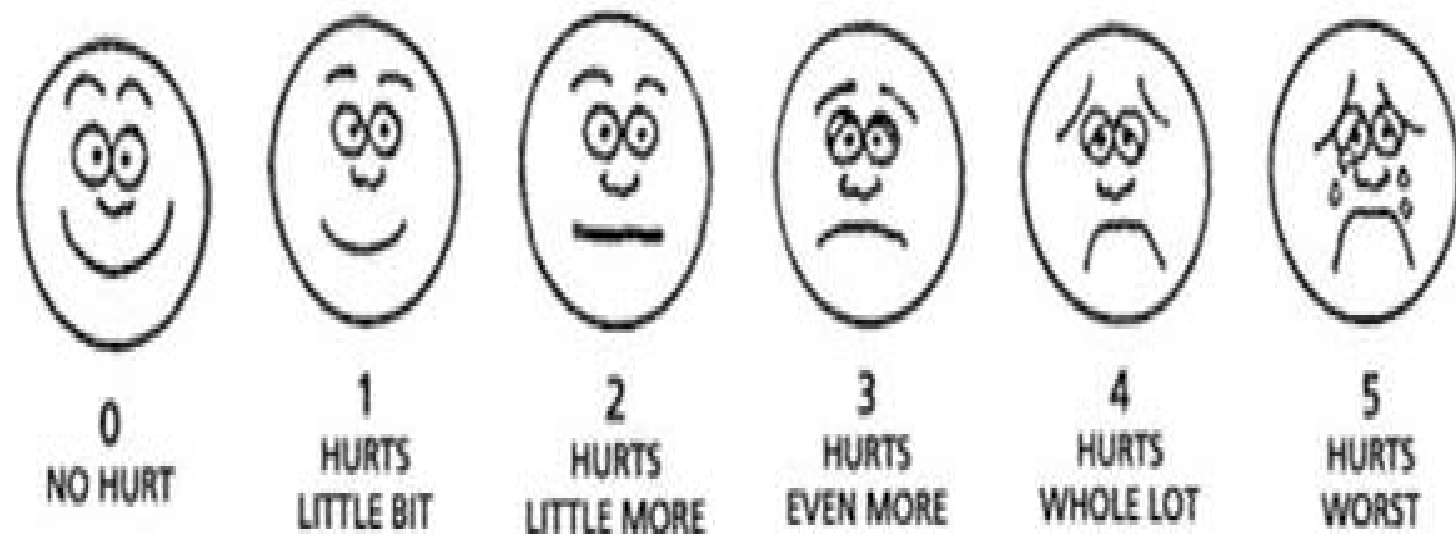

Figure 1. Wong Baker Rating Scale

\section{Materials and Methods}

A total of 110 patients in the age range of 8-11 years attending the paediatric dental OP of Thai Moogambigai Dental College and Hospital Chennai, were recruited for the study. The study was conducted from July 2013 to August 2013. A letter of consent was utilized to obtain consent from both parent and child to partake in the survey. The study population comprised of 44 children in the age group of 8,30 children in the age group 9 and 36 children in the age group 11 . Fears for dental procedures 
were assessed in these patients, using a structured questionnaire that was formulated keeping in mind the levels of fear for various situations to which they are subjected in the dental OPD. Children rated their fear intensity on a six-item ordinal faces scale (Wong-Baker Scale) ranging from none to worst. A questionnaire comprising of 10 questions was administered to each subject. Data Collection and Statistical Analysis was done. The responses of all the children were computed and grouped according to age. SPSS software version 15 was used to perform statistical analysis. Frequency of each of the study variables was analyzed. Chi Square test was used for intergroup comparison. $\mathrm{P}<0.05$ was considered statistically significant.

\section{Results}

All the 110 children completed the questionnaire. Table 1 comprises the question related to dental fear. The children of all the three groups expressed greatest fear for injections, followed by sound of drill during restorations. Children who gave a previous history of dental treatment had less fear compared to children with a history of first dental visit. The overall mean fear score was greatest among the 8 year old children and a declining trend in fear was observed as age increased. Figure 2 represents the mean fear score among the 8, 9, 11 year old children for the questions in the questionnaire.

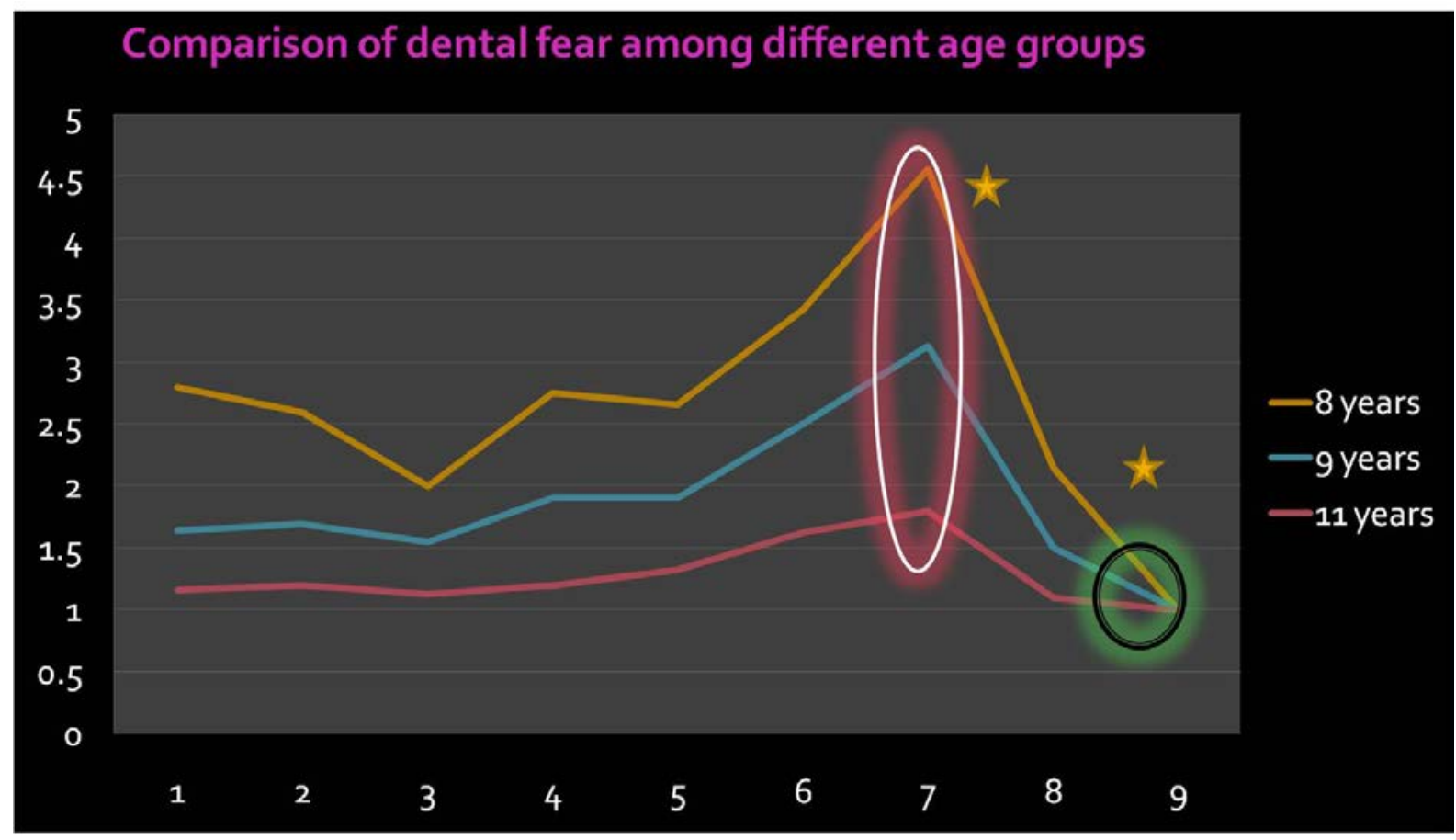

${ }^{\star}$ P VALUE -0.000, CHI SQUARE TEST, SIGNIFICANT

Figure 2. Comparison of Mean Dental Fear Score among the Three Age Groups

Table 1. Questionnaire

\begin{tabular}{ll}
\hline S.No & Question \\
\hline 0 & Have you been to the dental clinic before? \\
\hline 1 & If you had to go to the dental clinic tomorrow for a check-up, how would you feel about it? \\
\hline 3 & When you are waiting in the dental office for your turn, how do you feel? \\
\hline 4 & When you see another child getting his dental treatment done, how do you feel? \\
\hline 5 & $\begin{array}{l}\text { Imagine you are in the dental chair to have your teeth cleaned. While you are waiting and the dentist or hygienist is getting out the instruments } \\
\text { which will be used to scrape your teeth around the gums, how do you feel? }\end{array}$ \\
\hline 6 & When you are in the dental chair to get your decayed tooth filled and the dentist gets the dental drill, how do you feel? \\
\hline 8 & $\begin{array}{l}\text { When you are in the dental chair to have your tooth removed. While you are waiting and the dentist gets the injection which will be used to } \\
\text { numb your tooth, how do you feel? }\end{array}$ \\
\hline 9 & When the dentist takes a photograph of your tooth with specialized equipments, how do you feel? \\
\hline
\end{tabular}

\section{Discussion}

Bener et al 2011 [2] reported that the most common phobias observed among children were Social phobia $>$ Medical phobia > specific phobia. This indicated that medical and dental phobias are very common among children. Maria Carrillo-Diaz et al 2012 [7] stated that children's expectations of the likelihood and aversiveness of dental events are the two key points in understanding the development of dental fear. The results of the study indicate a decrease in fear with increase in age and children express fear most commonly for injections. Jana Olak et al 2013 [8] reported strong correlations between children's dental fear and their parent's dental fear. It was found that dental fear decreases with increase in age and 
children were most afraid of injections followed by noise of the dentist drilling. The result obtained in the present study is in accordance with those of Chhabra N et al 2012 [9] and Peretz B et al 2013 [10]. The present study demonstrated that children of 8 and 9 years age exhibited greater dental fear than 11 year olds. This is in line with the findings of Suprabha et al 2011 [11], who have suggested that younger the children higher the dental fear. The influence of age can be explained by the immature psychological development of children. In early childhood, fear towards unknown is prominent and by 9 years of age fears are linked to blood and body injuries, situations mostly encountered in a dental chair. Chapman HR et al 1999 [12] stated that dental fear among children has been recognized as a source of serious health problems and it may persist into adolescence leading to a disruptive behavior during dental treatment. The dental condition of patients with dental fear is generally worse than the condition of those without dental fear [13]. With providing the extra attention during dental treatment for children, we can reduce fear of dentist and dental treatment at an early age.

\section{References}

[1] Sunil Raj, Manisha Agarwal, Kiran Aradhya, Sapna Konde, V Nagakishore. Evaluation of dental fear in children during dental visit using the children's fear survey schedule dental subscale. Int J Clin Pediatr Dent 2013, 6(1): 12-15.

[2] Bener A, Ghuloum S, Dafeeah EE. Prevalence of common phobias and their socio-demographic correlates in children and adolescents in a traditional developing society. Afr J Psychiatry 2011; 14: 140-145.

[3] Klinberg G, Raadal M, Arnup K. Dental fear and behaviour management problems. In: Koch G, Poulsen S, eds. Pediatric Dentistry: A Clinical Approach. Singapore: Wiley-Blackwell Publishing; 2009.

[4] Nakai Y, Hirakawa T, Milgrom P et al. The children's Fear Survey Schedule-Dental Subscale in Japan. Community Dent Oral Epidemiol. 2005; 33:196-204.

[5] Gustafsson A. Dental behaviour management problems among children and adolescents-a matter of understanding? Studies on dental fear, personal characteristics and psycho-social concomitants. Swed Dent J Suppl 2010; 202: 1-46.

[6] Gustafson A, Arnrup K, Broberg AG, Bodin L, Berggren U. Psychosocial concomitants to dental fear and behaviour management problems. Int J Paediatr Dent 2007; 17: 449-59.

[7] Carrillo-Diaz M, Crego A, Armfield JM, Romero-Maroto M. Treatment experience, frequency of dental visits, and children's dental fear: a cognitive approach.Eur J Oral Sci 2012; 120: 75-81.

[8] Olak J, Saag M, Honkala S et al. Children's dental fear in relation to dental health and parental dental fear. Stomatologija. 2013; 15(1): 26-31.

[9] Chhabra N, Chhabra A, Walia G. Prevalence of dental anxiety and fear among five to ten year old children: a behaviour based cross sectional study. Minerva Stomatol. 2012;61(3):83-9.

[10] Peretz B, Kharouba J. Dental anxiety among Israeli children and adolescents in a dental clinic waiting room. Pediatr Dent. 2013;35(3):252-256

[11] Suprabha BS, Arathi Rao, Swetha Choudhary, Ramya Shenoy. Role of environmental factors in child dental fear and behavior. J Indian Soc Pedod Prev Dent 2011; 29: 95-101.

[12] Chapman HR, Kirby-Turner NC. Dental Fear in children - a proposed model. Br Dent J 1999; 187: 408-12.

[13] Bodner E, Iancu I. Recalling the Threat: Dental Anxiety in Patients Waiting for Dental Surgery. Isr J Psychiatry Relat Sci. 2013; 50: 61-66. 